\title{
Widespread low abundance despite habitat availability elevates extinction risk in pygmy seahorses
}

\author{
Maarten De Brauwer ${ }^{1,2}$ (1) Jean-Paul A. Hobbs ${ }^{3} \cdot$ Jamaluddin Jompa $^{4}$
}

Received: 24 April 2019/Accepted: 26 February 2020/Published online: 5 March 2020

(C) The Author(s) 2020

\begin{abstract}
Due to difficulties with surveying, cryptobenthic fishes are understudied, which limits assessments of their extinction risk. Using a novel survey method (a combination of underwater visual census and underwater biofluorescence census), we surveyed the densities of two gorgonian seafan-associated pygmy seahorses (Hippocampus bargibanti and $H$. denise) in 63 sites across Indonesia. Densities were low for both seahorses $(\leq 0.4$ seahorses/host) and their hosts $\left(\leq 0.25\right.$ seafans $\left./ 200 \mathrm{~m}^{2}\right)$. These low densities, combined with habitat specialisation, increase extinction risk. We failed to detect regional or depth patterns in seahorse abundance per host or group size in occupied hosts. Host occupancy rates were low $(<13.7 \%)$, suggesting that other factors than habitat availability constrain pygmy seahorse population size. The low densities found in this study highlight the high extinction vulnerability for habitat specialists on coral reefs.
\end{abstract}

Topical Editor Michael Lee Berumen

Electronic supplementary material The online version of this article (https://doi.org/10.1007/s00338-020-01913-x) contains supplementary material, which is available to authorized users.

Maarten De Brauwer

M.DeBrauwer@leeds.ac.uk

1 School of Biology, Faculty of Biological Sciences, University of Leeds, Leeds, UK

2 School of Molecular and Life Sciences, Curtin University, Perth, Australia

3 School of Biological Sciences, University of Queensland, Brisbane, QLD 4069, Australia

4 Faculty of Marine Science and Fisheries, Hasanuddin University, Makassar, Indonesia
Keywords Threatened species - IUCN red list . Syngnathidae $\cdot$ Habitat specialist $\cdot$ Symbiosis

\section{Introduction}

Cryptobenthic species represent a large proportion of reef fish diversity and play an important role in trophodynamics on coral reefs (Depczynski and Bellwood 2003). However, they are understudied due to difficulties with surveying, and thus, population declines can go unnoticed. The few dedicated surveys have shown that many cryptobenthic species are habitat specialists whose abundance declines rapidly following habitat loss (Munday 2004). Furthermore, the species that also have low abundance and rely on vulnerable habitats have the highest risk of extinction (Munday 2004). Habitat specialist reef fishes often show strong trends in spatial distribution, host preferences, and occupancy rates (Thompson et al. 2007; Camp et al. 2016), which can influence extinction risk patterns and provide refugia. Determining spatial patterns in the distribution, abundance, and habitat use of cryptobenthic habitat specialists will help assess their risk of extinction, a pertinent issue given the increasing habitat loss on coral reefs (Hughes et al. 2017).

Seahorses and pipefishes (Syngnathidae) are marine fishes vulnerable to extinction, with 18 species listed as endangered by International Union for the Conservation of Nature (IUCN 2019). Many other species are believed to be at risk of extinction; however, a lack of data often prevents listing, resulting in a data deficient classification (DD, IUCN 2019). Syngnathids are part of the cryptobenthic community and include many habitat specialists, such as pygmy seahorses. These species are among the smallest fishes on coral reefs and are habitat specialists that 
associate with Octocorallia, hydrozoans, seagrasses, and algae (Short et al. 2018). Pygmy seahorses also appear to have low abundance (Smith et al. 2012), which would increase extinction risk. However, their small size $(<3 \mathrm{~cm}$ SL (Gomon 1997)) and excellent camouflage have hampered efforts to gather sufficient data to formally assess extinction risk (IUCN: DD for all members except Hippocampus pontohi) (IUCN 2019; Pollom 2017). Consequently, range contractions and declines in abundance could go undetected.

Pygmy seahorses are also commercially important because they are one of the most sought after viewing experiences by scuba divers visiting Indonesia (Smith 2010; De Brauwer and Burton 2018). Indonesia is a global hotspot for coral reef biodiversity and is home to five pygmy seahorse species (Smith 2010). Coral reef tourism is an important source of income for coastal communities in developing nations, and dive tourism is particularly dependant on healthy reef ecosystems. The economic value of species such as pygmy seahorses highlights the importance of developing efficient conservation strategies based on accurate data. At present, critical ecological knowledge such as host saturation, depth distribution, and regional variations in abundance remains unknown.

Patterns in abundance and habitat use across the geographic range of habitat specialists are important factors that influence extinction risk (Munday 2004), and this data is needed for formally assessing extinction risk. This critical information is often lacking for species such as pygmy seahorses since traditional visual survey methods fail to accurately detect small, cryptic species (De Brauwer et al. 2018). However, a recently developed survey method, underwater biofluorescence census (UBC), has been shown to increase detection rates of cryptobenthic species (De Brauwer et al. 2018). This now provides a tool to gather the necessary data to assess extinction risk in small cryptic reef fishes. The purpose of this study was to survey two data deficient pygmy seahorse species that are obligate symbionts with gorgonian seafans. In this study, we specifically tested the aims:

1. Do $H$. bargibanti and $H$. denise and their host seafans have low abundances across Indonesia?

2. Does the abundance and group size of $H$. bargibanti change significantly with location, depth, and host seafan size?

\section{Methods}

\section{Focal species}

Surveys focused on two pygmy seahorse species: $H$. bargibanti (Whitley 1970, redescribed by Gomon 1997) and
H. denise (Lourie and Randall 2003). Both species have an obligate symbiotic relationship with gorgonian seafans; $H$. bargibanti is found on the surface of seafans of the genus Muricella (Gomon 1997; Reijnen et al. 2011), and $H$. denise is associated with up to nine host species, of which the most commonly inhabited host seafan genera are $A n$ nella and Villogorgia. Less frequent associations include the genera Acanthogorgia, Echinogorgia, and Melithaea. (Lourie and Randall 2003; Reijnen et al. 2011; Smith et al. 2012).

\section{Study sites}

Surveys were conducted between July 2015 and December 2015 at 63 sites in four regions (Bali, Nusa Tenggara, North Sulawesi, Raja Ampat) in Indonesia (Fig. 1; Site list in ESM).

In Bali, surveys were conducted on the north coast, and sites included sloping reefs and coral reef walls. Sites in Nusa Tenggara consisted of sloping coral reefs, exposed ocean pinnacles, and coral reef walls exposed to strong currents. North Sulawesi sites included sheltered bays, open ocean drop-offs, and patch reefs with strong tidal currents. Sites in north Raja Ampat were sloping reefs with moderate to high coral cover, while sites in the south consisted of drop-offs and pinnacles with high coral cover.

An inherent risk of visiting sites used by scuba tourism operators is introducing a bias towards high abundance sites. To reduce this potential bias, surveys were conducted (within logistical and safety constraints) without local dive guides and included sites not frequented by tourists.

\section{Survey methods}

Underwater visual surveys (UVC) were conducted by MDB on scuba, to a maximum depth of $40 \mathrm{~m}$. With time limitations inherent to any UVC, it is important to acknowledge the relatively small percentage of potential habitat that can be surveyed. Due to these restrictions, combined with the low abundance of host gorgonian seafans (Reijnen et al. 2011) and the depth of dives, surveys focused on only the most commonly used host species. Seafan hosts (Muricella spp., Annella spp., and Villogorgia spp.) encountered during the 60-min dives were surveyed using two complimentary techniques. UVC and UBC were used to detect pygmy seahorses; UBC was shown to double detection rates of pygmy seahorses in a previous study (De Brauwer et al. 2018). An initial 2-min visual survey searched the entire area of the seafan. The same gorgonian was then scanned for two more min using a fluorescence torch (Sola Nightsea) and yellow barrier filter (detailed description in De Brauwer et al. 2018) to detect additional seahorses. The order of both search methods was reversed 


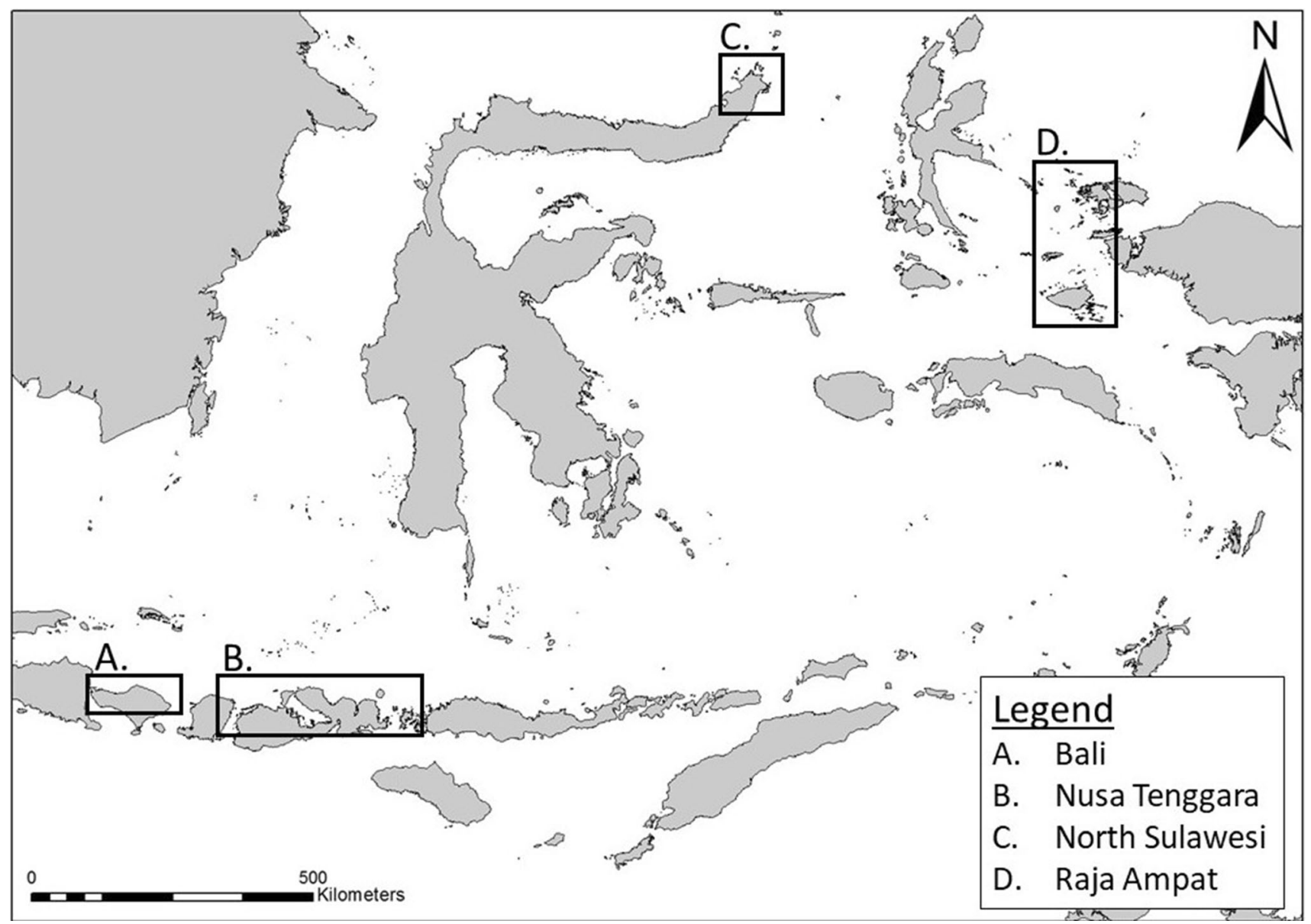

Fig. 1 Map of regions in Indonesia where pygmy seahorses were surveyed

randomly between hosts. The seafan and a close-up of the polyps were photographed post-observation to allow for identification. The depth and seafan surface area were recorded after completing pygmy seahorse surveys. Host seafan surface area was estimated by measuring the height (base to farthest point) and multiplying this by the diameter (widest part) (Smith et al. 2012).

Host seafan density was estimated during timed swims separate from pygmy seahorse observations but at the same sites. Densities were estimated by counting seafans on a 20-m-wide belt transect at a depth of $15 \mathrm{~m}$. The distance covered during each swim was estimated at $0.6 \mathrm{~m} \mathrm{~s}^{-1}$ by swimming a set distance $(30 \mathrm{~m})$ multiple times $(>200)$ to arrive at an average $(45 \mathrm{~s})$. Density was standardised to $200 \mathrm{~m}^{2}$ prior to data analysis. These surveys were only conducted on sites in North Sulawesi and Bali. Seafan density estimates could not be obtained at Nusa Tenggara and Raja Ampat due to strong currents.

\section{Analysis}

Abundance data and host seafan occupation rates were calculated and visualised using RStudio ( $\mathrm{R}$ Core Team 2015). Effects of depth, seafan area, and regional differences were only analysed for $H$. bargibanti as the low sample size of $H$. denise $(N=7)$ was prohibitive for further analysis. As data did not meet assumptions of normality, regional differences in $H$. bargibanti abundance were tested using Kruskal-Wallis tests. Effects of depth and host seafan areas were tested with Spearman rank correlations tests.

Seafan densities of Muricella spp. and Annella spp. were square root transformed, and differences between regions were tested using one-way ANOVA. Tukey post-hoc tests were used to test significant differences. Villogorgia spp. data did not meet assumptions of normality; KruskalWallis tests were used to detect regional differences. 


\section{Results and discussion}

A total of 275 host gorgonians seafans were observed and comprised of Muricella spp. $(n=146)$, Annella spp. (110), and Villogorgia spp. $(n=19)$. We counted $64 H$. bargibanti individuals and seven $H$. denise. The occupancy rate of $H$. bargibanti in Muricella spp. was low at $13.7 \%$. Hippocampus denise occupancy rates in Annella spp. were lower than in Villogorgia spp. (respectively, 2.7\% and $10.5 \%$ ) (Table 1). Group size for H. bargibanti ranged from 1 individual to 10 individuals per occupied host and 1-3 individuals per host for $H$. denise. True abundance of $H$. denise could be higher than suggested in this study, as not all potential hosts were surveyed. For example, Melithaea sp. seafans in the Raja Ampat could be an important host but were not included here.

Hippocampus bargibanti abundance per seafan did not differ between the surveyed regions $\left(\mathrm{KW}: \chi^{2}=2.3242\right.$, $d f=3, p$ value $=0.5079$, Fig. 2 ), neither did group size in occupied seafans (KW: $\chi^{2}=6.27, \quad d f=3$, $p$ value $=0.0991)$.

Even though they are highly valued by the tourism sector (Smith 2010; De Brauwer and Burton 2018), the population size and extinction risk of pygmy seahorses remain unclear (IUCN 2019). This study represents the first large-scale study to investigate pygmy seahorse abundance on a national scale and showed even lower abundance than the previous studies. The only published previous studies used UVC and focused on a single region or on a limited number of host seafans in one location (Baine et al. 2008; Smith et al. 2012). The abundances and occupancy rates of both $H$. bargibanti and $H$. denise across Indonesia in this study were even lower than previously recorded data from the Wakatobi National Park (Smith et al. 2012).

This trend was also noted in host seafan density in Bali and North Sulawesi, with densities in this study lower than those in Wakatobi (Smith et al. 2012). The density for Muricella spp. seafans was 0.25 ( \pm SE 0.06) seafans/ $200 \mathrm{~m}^{2}$, with a mean seafan size of $0.84 \mathrm{~m}^{2}( \pm \mathrm{SE}$ $\left.0.06 \mathrm{~m}^{2}\right)$. Density of Annella spp. was 0.21 ( \pm SE 0.04) seafans $/ 200 \mathrm{~m}^{2}$ and a mean size of $0.73 \mathrm{~m}^{2}( \pm \mathrm{SE}$ $0.06 \mathrm{~m}^{2}$ ). The mean density of Villogorgia spp. seafans was $0.03( \pm \mathrm{SE} 0.01)$ seafans $/ 200 \mathrm{~m}^{2}$, with a mean seafan size of $0.32 \mathrm{~m}^{2}\left( \pm\right.$ SE $\left.0.05 \mathrm{~m}^{2}\right)$.

Protective measures in the Wakatobi National Park could explain the differences in seahorse and seafan abundance in the previous studies (Smith et al. 2012). Future research comparing protected areas such as Komodo and Raja Ampat with non-protected reefs could inform potential drivers of regional variation in abundances. Although seafans are vulnerable to a range of impacts, to the best of our knowledge, there is no information available on temporal changes in seafan densities. However, the obligate relationship between both species suggests that declines in seafan abundance are likely to have a significant impact on pygmy seahorses.

Muricella spp. showed regional differences in seafan density $\left(F_{(3,18)}=4.17, p=0.02\right)$; post-hoc tests indicated that the higher densities in Lembeh Strait compared to Bunaken were the only significantly different sites $(p=0.01)$. There were no regional differences for Annella spp. $\left(F_{(3,18)}=0.86, p=0.48\right)$ or Villogorgia spp. (KW test: $\left.\chi^{2}(3)=6.3962, p=0.09\right)$.

Spearman rank tests did not detect significant correlations between $H$. bargibanti abundance and their host seafan size $(r=-0.17, p=0.10)$ or depth $(r=-0.08$, $p=0.31$ ). Correlations between group size in occupied seafans and seafan size $(r=-0.18, p=0.46)$ or depth $(r=-0.34, p=0.13)$ were not significant either. These results confirm the previous studies which also failed to detect effects of depth or seafan area on $H$. bargibanti abundance (Smith et al. 2012). Smith et al. (2012) did, however, find a correlation between group size and host area.

The low densities of both hosts and pygmy seahorses reported in this study, combined with similar results in previous studies, suggest low densities throughout their entire range. Results for $H$. denise need to interpreted with caution, however, as not all hosts were included in surveys. The combination of low abundance and habitat specialisation greatly increases the risk of extinction for pygmy seahorses (Munday 2004). Habitat specialists such as pygmy seahorses are predicted to be most impacted by declining coral reef health (Wilson et al. 2008). However,
Table 1 Summary statistics of Hippocampus bargibanti and $H$. denise abundance in Indonesia

\begin{tabular}{lll}
\hline & H. bargibanti & H. denise \\
\hline Seahorses $(N)$ & 64 & 7 \\
Seafans surveyed & 146 & 129 \\
Seafan area surveyed & $122.6 \mathrm{~m}^{2}$ & $86.0 \mathrm{~m}^{2}$ \\
Occupied seafans & 20 & 5 \\
Percentage occupied seafans & $13.7 \%$ & $3.9 \%$ \\
Abundance per seafan (Mean $\pm \mathrm{SE})$ & $0.4( \pm 0.12)$ & $0.05( \pm 0.03)$ \\
Occupied seafans: group size $($ Mean $\pm \mathrm{SE})$ & $3.2( \pm 0.57)$ & $1.4( \pm 0.4)$ \\
\hline
\end{tabular}




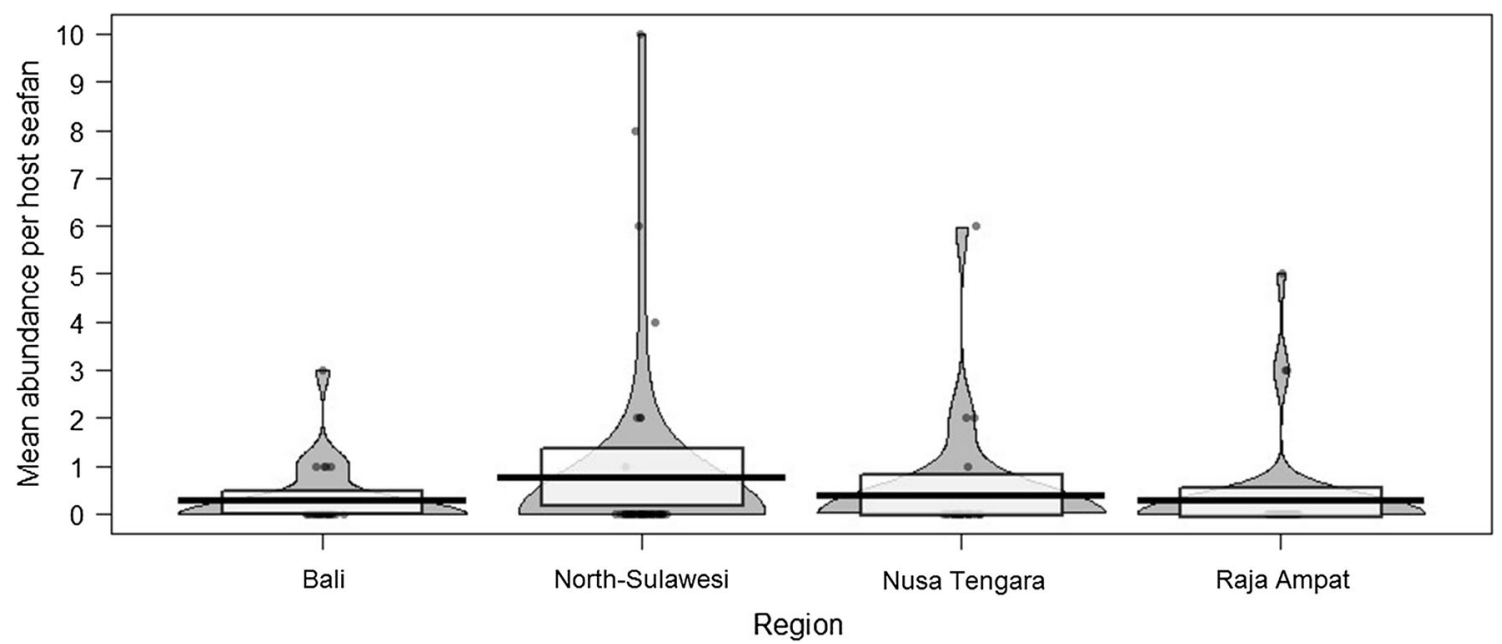

Fig. 2 Pirate plot of Hippocampus bargibanti abundance in Muricella spp. seafans across four regions in Indonesia. Black bar indicates mean, white rectangle shows $95 \%$ confidence interval, and dots represent data points

the low occupancy rates "despite available habitat" also indicate that factors other than habitat availability are constraining population sizes. Potential factors that could affect host occupancy rates include, but are not limited to, the presence of conspecifics at the settlement stage, physical characteristics of the host seafan, or dispersal dynamics at the larval stage (Lecchini et al. 2007). Determining what these factors are is critical to assess extinction risk of pygmy seahorses.

The cryptic nature of many habitat specialists such as pygmy seahorses presents a major difficulty for collecting accurate abundance data needed to assess their extinction risk. Methods such as eDNA or UBC have shown promise but need to be further developed to be of practical use for resource managers (DiBattista et al. 2017; De Brauwer et al. 2018). The UBC method allows for more rapid, more comprehensive, and more reliable assessments of cryptic species abundance. Used in combination with novel molecular methods, it could offer a useful alternative to UVC for surveying gorgonians to estimate pygmy seahorse numbers.

This study found low densities of $H$. bargibanti and $H$. denise and their respective host gorgonian seafans. Seahorse abundance per seafan did not vary regionally, but there were regional differences in the density of host gorgonian seafans. Host occupancy rates were low despite habitat availability, suggesting that other factors, potentially at the larval settlement stage, constrain pygmy seahorse population size. While other factors may influence the population dynamics of pygmy seahorses, ongoing habitat degradation on coral reefs is certain to negatively affect the extinction risk of these obligate coral symbionts. Therefore, in the absence of full knowledge on which other factors affect extinction risk, we suggest that conservation efforts should focus on protecting valuable habitat, such as areas of high seafan abundance. The low pygmy seahorse densities found in this study highlight the need for increased protection and a better understanding of the ecology of these iconic species and other habitat specialists on coral reefs. Failing to do so might result in the loss of some of the world's most distinctive fish species.

Acknowledgements Logistical support was provided by Critters@Lembeh, Froggies Divers, Nomad Divers Bangka, Safari Bali, and Sea Safari. Research within Indonesia was permitted through a RISTEK research permit granted to MDB in collaboration with JJ. A Society for Conservation Biology Marine Section Small Grant provided funding for surveys in Bangka Island. JPH is funded by ARC-DE200101286.

Open Access This article is licensed under a Creative Commons Attribution 4.0 International License, which permits use, sharing, adaptation, distribution and reproduction in any medium or format, as long as you give appropriate credit to the original author(s) and the source, provide a link to the Creative Commons licence, and indicate if changes were made. The images or other third party material in this article are included in the article's Creative Commons licence, unless indicated otherwise in a credit line to the material. If material is not included in the article's Creative Commons licence and your intended use is not permitted by statutory regulation or exceeds the permitted use, you will need to obtain permission directly from the copyright holder. To view a copy of this licence, visit http://creativecommons. org/licenses/by/4.0/.

\section{References}

Baine MSP, Barrows APW, Ganiga G, Martin-Smith KM (2008) Residence and movement of pygmy seahorses, Hippocampus bargibanti, on seafans (Muricella spp.). Coral Reefs 27:421

Camp EF, Hobbs JPA, De Brauwer M, Dumbrell AJ, Smith DJ (2016) Cohabitation promotes high diversity of clownfishes in the Coral Triangle. Proc Soc B: 283 
De Brauwer M, Burton M (2018) Known unknowns: Conservation and research priorities for soft sediment fauna that supports a valuable SCUBA diving industry. Ocean Coast Manage 160:30-37

De Brauwer M, Hobbs JPA, Ambo-Rappe R, Jompa J, Harvey ES, McIlwain JL (2018) Biofluorescence as a survey tool for cryptic marine species. Cons Biol 32:706-715

DiBattista JD, Coker DJ, Sinclair-Taylor TH, Stat M, Berumen ML, Bunce M (2017) Assessing the utility of eDNA as a tool to survey reef-fish communities in the Red Sea. Coral Reefs 36:1245-1252

Depczynski M, Bellwood DR (2003) The role of cryptobenthic reef fishes in coral reef trophodynamics. Mar Ecol Prog Ser 256:183-191

Gomon M (1997) A remarkable new pygmy seahorse (Syngnathidae: Hippocampus) from Southeastern Australia, with a redescription of $H$. bargibanti Whitley from New Caledonia. Memoirs of the Museum of Victoria 56:245-253

Hughes TP, Barnes ML, Bellwood DR, Cinner JE, Cumming GS, Jackson JB, Kleypas J, Van De Leemput IA, Lough JM, Morrison TH, Palumbi SR (2017) Coral reefs in the Anthropocene. Nature 546:82-90

IUCN (2019) The IUCN Red List of Threatened Species. Version 2019-1. https://www.iucnredlist.org

Kuo T-C, Pollom R (2017) Hippocampus denise. The IUCN Red List of Threatened Species 2017: e.T41716A54909161. https://doi. org/10.2305/iucn.uk.2017-3.rlts.t41716a54909161.en

Lecchini D, Planes S, Galzin R (2007) The influence of habitat characteristics and conspecifics on attraction and survival of coral reef fish juveniles. J Exp Mar Biol Ecol 341:85-90

Lourie SA, Randall JE (2003) A new pygmy seahorse, Hippocampus denise (Teleostei Syngnathidae) from the Indo-Pacific. Zoological studies-Taipei 42:284-291

Munday PL (2004) Habitat loss, resource specialization, and extinction on coral reefs. Global Change Biol 10:1642-1647
Pollom R (2017) Hippocampus bargibanti. The IUCN Red List of Threatened Species 2017: e.T10060A54904073. https://doi.org/ 10.2305/iucn.uk.2017-3.rlts.t10060a54904073.en

R Development Core Team (2015) R: A Language and Environment for Statistical Computing. R Foundation for Statistical Computing, Vienna

Reijnen BT, van der Meij SET, van Ofwegen LP (2011) Fish, fans and hydroids: host species of pygmy seahorses. ZooKeys 103:1-26

Short G, Smith R, Motomura H, Harasti D, Hamilton H (2018) Hippocampus japapigu, a new species of pygmy seahorse from Japan, with a redescription of $H$. pontohi (Teleostei, Syngnathidae). ZooKeys 779:27-49

Smith RE (2010) The biology and conservation of gorgonianassociated pygmy seahorses. $\mathrm{PhD}$ thesis, School of Biological Sciences, The University of Queensland, St. Lucia, Queensland

Smith RE, Grutter AS, Tibbetts IR (2012) Extreme habitat specialisation and population structure of two gorgonian-associated pygmy seahorses. Mar Ecol Prog Ser 444:195-206

Thompson VJ, Munday PL, Jones GP (2007) Habitat patch size and mating system as determinants of social group size in coraldwelling fishes. Coral Reefs 26:165-174

Wilson SK, Burgess SC, Cheal AJ, Emslie M, Fisher R, Miller I, Polunin NV, Sweatman H (2008) Habitat utilization by coral reef fish: implications for specialists vs. generalists in a changing environment. J Animal Ecol 77:220-228

Whitley G (1970) Bargibant's seahorse from New Caledonia. Proceedings of the Linnean Society of New South Wales. Linnean Society of New South Wales Kingsford, New South Wales

Publisher's Note Springer Nature remains neutral with regard to jurisdictional claims in published maps and institutional affiliations. 